\title{
Obsevisto
}

ISSN n² 2447-4266

Vol. 1, n², Setembro-dezembro. 2015

DOI: http://dx.doi.org/10.20873/uft.2447-4266.2015v1n2p194

\section{Turismo e \\ desenvolvimento \\ regional: atrativos \\ turísticos}

Tourism and regional development: tourist attractions

Turismo y desarrollo

regional: atractivos turísticos

\section{Moacir José Santos ${ }^{1}$ \\ Fernando Hanaoka ${ }^{2,3}$}

\section{RESUMO}

O presente artigo tem como objetivo apresentar caracterizar a Microrregião de Bananal a partir da identificação dos seus atrativos na Estrada Real - Caminho Novo da Piedade, nos municípios de Areias e Bananal dentro do território denominado como Vale Histórico, para apontar ações realizadas ou que possam vir a ser para o desenvolvimento daquele local, contemplando essencialmente a preservação de elementos históricos compatibilizados com o meio-ambiente urbano e a atividade turística contemporânea. Após a decadência do ciclo do café no Vale do Paraíba Paulista, espaços como fazendas, caminhos coloniais e municípios se voltam para a prática da atividade turística, explorando sua história, sua cultura, suas edificações, e seus recursos naturais e culturais como uma alternativa no processo econômico da região. Diante das afinidades históricas, culturais e geográficas encontradas entre os municípios de Areias e Bananal optou-se por destacá-los na identificação dos

\footnotetext{
${ }^{1}$ Doutor, mestre e graduado em História pela Universidade Estadual Paulista Júlio de Mesquita Filho (UNESP). Pós-doutor pela Universidade do Minho (UMINHO). Professor do Programa de Mestrado em Planejamento e Desenvolvimento Regional (Universidade de Taubaté). E-mail: santos.mj@ig.com.br.

2 Mestre em Planejamento e Desenvolvimento Regional. Professor do IESP. E-mail: fernando.hanaoka@gmail.com.

${ }^{3}$ Endereço de contato dos autores (por correio): Universidade de Taubaté. Programa de Mestrado em Planejamento e Desenvolvimento Regional. Avenida Granadeiro Guimarães, 270 - Centro, Taubaté SP, Brasil. CEP: 12020-130.
} 


\section{Oésisto}

ISSN n² 2447-4266

Vol. 1, n² 2, Setembro-dezembro. 2015

DOI: http://dx.doi.org/10.20873/uft.2447-4266.2015v1n2p194

atrativos turísticos do Vale Histórico na Estrada Real - Caminho Novo da Piedade. A pesquisa caracterizou-se como exploratória descritiva com abordagem qualitativa, com base na qual se pretende estudar dados socioeconômicos além de identificar seus atrativos turísticos, propondo analisar a economia na região delimitada. Os resultados indicam ausência de uma política pública consistente para o desenvolvimento turístico em relação ao potencial apresentado na região. Conclui-se que somente a elaboração e efetivação de uma política pública dedicada a promover um circuito turístico integrado na microrregião produzirão benefícios para a geração de emprego e renda e, simultaneamente, a preservação do patrimônio histórico.

PALAVRAS-CHAVE: Desenvolvimento regional; turismo; microrregião de Bananal.

\section{ABSTRACT}

This article aims to present characterize Bananal from the identification of its attractions in Estrada Real - Caminho Novo da Piedade, in the municipalities of Areias and Bananal within the territory referred to as Vale Histórico, to point actions taken or they may be for the development of that place, essentially covering the preservation of historic elements made compatible with the urban environment and contemporary tourism. After the decline of the coffee cycle in the Vale do Paraíba Paulista, places like farms, colonial ways and municipalities turn to the practice of tourism, exploring its history, its culture, its buildings, and its natural and cultural resources as an alternative to economic process of the region. On the historical, cultural and geographic affinities found between the towns of Areias and Bananal we chose to highlight them in the identification of the tourist attractions of the Estrada Real - Caminho Novo da Piedade. The research was characterized as descriptive exploratory with a qualitative approach, based on which we intend to study socioeconomic data and identify its tourist attractions, proposing to analyze the economy in the region delimited. The results indicate the absence of a consistent public policy for tourism development in relation to the potential presented in the region. It follows that only the elaboration and execution of public policy dedicated to promoting an integrated tourist circuit in the micro will produce benefits for the generation of employment and income and simultaneously, the preservation of historical heritage. 


\section{Obevisto}

ISSN n² 2447-4266

Vol. 1, n², Setembro-dezembro. 2015

DOI: http://dx.doi.org/10.20873/uft.2447-4266.2015v1n2p194

KEYWORDS: Regional development; tourism; Bananal.

\section{RESUMEN}

Este artículo tiene como objetivo presentar caracterizar la microrregión de Bananal de la identificación de los lugares de interés en Estrada Real - Caminho Novo da Piedade, en los municipios de Areias y Bananal en el territorio denominado Valle Histórico, para señalar las medidas adoptadas o puede ser para el desarrollo de ese lugar, cubriendo esencialmente la preservación de elementos históricos hechos compatibles con el medio ambiente urbano y el turismo contemporáneo. Después de la decadencia del ciclo de café en el Vale do Paraíba Paulista, lugares como granjas, caminos coloniales y municipios recurrir a la práctica del turismo, la exploración de su historia, su cultura, sus edificios, y sus recursos naturales y culturales como una alternativa a proceso económico de la región. En las afinidades históricas, culturales y geográficas que se encuentran entre los municipios de Arenas y Bananal elegimos para resaltarlos en la identificación de los lugares de interés turístico del Valle Histórico en Estrada Real - Caminho Novo da Piedade. La investigación se caracteriza por ser exploratorio descriptivo con abordaje cualitativo, con base en el cual tenemos la intención de estudiar los datos socioeconómicos e identificar sus atractivos turísticos, proponiendo para analizar la economía en la región delimitada. Los resultados indican la ausencia de una política pública consistente para el desarrollo del turismo en relación con el potencial se presenta en la región. De ello se desprende que sólo la elaboración y ejecución de políticas públicas dedicadas a la promoción de un circuito turístico integrado en el micro producirá beneficios para la generación de empleo y e.simultaneamente ingresos, la conservación del patrimonio histórico.

PALABRAS CLAVE: Desarrollo regional; turismo; Bananal.

Recebido em: 22.09.2015. Aceito em: 01.12.2015. Publicado em 08.12.2015. 


\section{Obevisto \\ DOI: http://dx.doi.org/10.20873/uft.2447-4266.2015v1n2p194}

\section{Introdução}

O Vale do Paraíba experimentou forte crescimento econômico com a cultura do café a partir do século XIX, nesse contexto seu desenvolvimento produziu enriquecimento da sua cultura por meio de um legado histórico de patrimônio arquitetônico que hoje constituem como atrativos turísticos.

No Brasil o setor turístico tem sua força econômica crescente. Novos destinos são sucessivamente descobertos e aproveitados como locais com potencial turístico, o que permite a criação de novas atividades, oportunidades de trabalho e o desenvolvimento local e regional.

Segundo Beni (1998), o turismo provoca o desenvolvimento intersetorial, em função do efeito multiplicador do investimento e dos fortes crescimentos da demanda interna e receptiva. É atividade excelente para obtenção de melhores resultados no desenvolvimento e planejamento regional ou territorial. Por efeito do aumento da oferta turística (alojamentos, estabelecimentos de alimentação, indústrias complementares e outros), eleva a demanda de emprego, repercutindo na diminuição da mão-de-obra subutilizada ou desempregada.

A proposta do trabalho é relacionada sob alguns aspectos: o desenvolvimento regional, o turismo, a Estrada Real Caminho Novo da Piedade, a motivação do turista e as fazendas históricas do café no Vale do Paraíba Paulista.

As fazendas no passado já foram de grande importância para a região, hoje desativadas, algumas abandonadas, outras transformadas em hotéis e outras tombadas como patrimônio histórico cultural. Isoladas em sua maioria, pelo tempo e pelo desuso, as fazendas remanescentes do ciclo do café, impressionam pela imponência das edificações típicas desses casarões cuidadosamente planejados para demonstrar poder. 


\title{
Obsevisto
}

ISSN n² 2447-4266

Vol. 1, n², Setembro-dezembro. 2015

DOI: http://dx.doi.org/10.20873/uft.2447-4266.2015v1n2p194

Quanto a sua importância histórica para o desenvolvimento do Vale do Paraíba Paulista, Carrilho comenta:

\begin{abstract}
Uma das áreas pioneiras de desenvolvimento da cultura do café teve origem no chamado Caminho Novo da Piedade, ligação terrestre aberta no século XVIII entre as províncias de São Paulo e do Rio de Janeiro. Iniciada a partir de Lorena, essa estrada passa por Silveiras, Areias, São José do Barreiro e Bananal [...], Esta região, conhecida como o "fundo do vale" assistiu, durante o século XIX, um vertiginoso processo de desenvolvimento, dando origem à formação de alguns dos mais ricos estabelecimentos de café daquele período. (CARRILHO,2006).
\end{abstract}

Este trabalho propõe analisar o turismo quanto ao segmento do turismo histórico, seus agentes econômicos na relação com o desenvolvimento do Vale do Paraíba Paulista, o objeto de estudo passou a ser, portanto, um recorte da Estrada Real - Caminho Novo da Piedade entre o período colonial do ciclo do café e da atividade turística contemporânea.

A definição pelo recorte resulta na escolha do perfil de duas cidades com maiores atributos e organização turística. Dessa forma, poderá ser avaliado o potencial da economia do turismo, advindo do fluxo de turistas na região frente ao desenvolvimento regional.

\section{Desenvolvimento Regional e o Turismo}

Putnam (2005) explica que para uma região desenvolver-se em relação à outra, deve-se considerar um fator essencial - "a atuação de seus atores locais", já que quanto maior for a articulação regional com políticas públicas, em busca do desenvolvimento, maior será a possibilidade da região ter um desenvolvimento mais assertivo e sólido. Entretanto, estes não podem atuar separadamente, já que eles dependem que alguém faça as amarrações necessárias. 


\section{Obrevisto}

ISSN n² 2447-4266

Vol. 1, n 2, Setembro-dezembro. 2015

DOI: http://dx.doi.org/10.20873/uft.2447-4266.2015v1n2p194

No Brasil, o setor de serviços, vem atraindo de modo progressivo à atenção dos governantes e demais autoridades responsáveis pelo planejamento de políticas públicas, por se tratar de um setor com grande vocação para a geração de emprego, renda e desenvolvimento socioeconômico, constituindo um efeito importante em termos de política econômica.

Desde a década de 60 , sob a ótica de que os serviços equivalem a bens imateriais, que são apenas complementos dos bens materiais necessários para o crescimento econômico, alguns autores já discutiam a contribuição das atividades e ocupações de serviços para a dinâmica do processo de desenvolvimento. Existem três conjuntos de explicações clássicas para analisar o crescimento das atividades de serviços:

1. A primeira explicação concentra-se na análise das razões das mudanças relativas e absolutas do emprego no setor terciário, descrevendo o fenômeno da terceirização como um processo que conduz à sociedade de serviços, existe diferenças nas produtividades dos serviços e das manufaturas, e o setor terciário é um escoadouro para o excedente de mão de obra do setor de produção de bens. (KON apud BAILY e MAILLAT 1991).

2. A segunda forma de analisar o fenômeno salientado por Kon (2004), explica que a terceirização é um resultado do declínio relativo e absoluto do emprego no setor secundário subsequente ao desenvolvimento de novas tecnologias mais produtivas. Esse declínio é também observado como o efeito do consumo decrescente de bens industriais. Neste caso, o setor terciário reabsorve a mão de obra dispensada, e a realocação de capital para o setor de serviços é efetuada com maiores retornos e rentabilidade. 


\section{Obevisto}

ISSN n² 2447-4266

Vol. 1, n², Setembro-dezembro. 2015

DOI: http://dx.doi.org/10.20873/uft.2447-4266.2015v1n2p194

3. Por fim, o terceiro conjunto de explicações segundo Kon (2004), aponta que a queda do emprego no setor secundário se deve ao crescimento do emprego no setor público, sendo uma consequência do aumento da demanda por serviços coletivos. Ao analisarmos o terceiro conjunto é possível detectar uma similaridade com a recente história econômica do $A B C$ paulista aonde se pode destacar as fases dessas mudanças desde a expansão das fábricas no $A B C$ paulista (industrialização), o período do sindicalismo e o crescimento do funcionalismo público.

Amin (2008) argumenta que o conceito de desenvolvimento está diretamente ligado à "nova política regional", que converge para uma única relação, definida entre as cidades, regiões e clusters, sob uma perspectiva contemporânea, considerando que há um enlace cultural.

Algumas regiões brasileiras se apresentam com amplos potenciais de desenvolvimento no âmbito do turismo. A costa brasileira detém um dos principais recursos naturais, o litoral é um grande receptor de investimentos turísticos mundiais. Os estados que compõem a região apresentam um grande potencial ou vocação turística, haja vista seus inúmeros atrativos.

O cenário brasileiro demonstra que o Turismo está conquistando espaço definitivo junto aos diversos setores da economia, em larga escala, o turismo, que tem apresentado resultados excepcionais permite em termos de crescimento econômico colaborar de forma significativa com a geração de empregos, aumento de renda e geração de divisas, em termos de desenvolvimento econômico colabora de forma significante, diminuindo as diferenças regionais e melhorando a qualidade de vida de populações de regiões mais atrasadas, pela execução de obras de 


\section{Obevisto}

ISSN n² 2447-4266

Vol. 1, n 2, Setembro-dezembro. 2015

DOI: http://dx.doi.org/10.20873/uft.2447-4266.2015v1n2p194

infraestrutura, incluindo transporte, saneamento, energia entre outros. (LAGE e MILONE, 2004).

Para prosseguirmos na análise da questão do turismo e sua contribuição para o desenvolvimento regional, devemos concluir que a atividade do turismo necessitará de uma visão holística bem mais ampla para sua compreensão e neste caso, procura-se abranger a essência total do assunto.

Muitos são os exemplos de um modelo integrado aonde à atividade tornou-se algumas regiões a melhor alternativa para o desenvolvimento, há exemplos internacionais como a Espanha e Alemanha, o que demonstra uma grande possibilidade para a região em questão.

O Turismo não está apenas relacionado com o espaço físico e sua prática do lazer ele também engloba o ambiente cultural, histórico, social e econômico e envolve um grande número de interessados. As comunidades têm ao mesmo tempo responsabilidades e direitos.

A atividade turística tem a premissa de beneficiar a todos promovendo o desenvolvimento integrado entre as bases dos fundamentos do turismo: a comunidade, o setor público e o setor privado. Essa relação propõe ações integradas para o desenvolvimento das localidades e exige-se certa postura do setor, através de sua rede de relações denominada por Silva (2000) como "Rede Turística".

Nas relações comerciais, é fato compreendermos a conexão entre várias empresas com propósito mercantil, suas especificidades, seus produtos, sua relação de compra e venda enfim, seu negócio. A Rede Turística trata o assunto, sobre a perspectiva de uma rede de serviços, observando suas conexões e seu potencial que afirmará sua força econômica para o setor.

De maneira ampla existe um conjunto composto por uma gama de organizações e de atores, formando o que foi denominado aqui de rede turística. Os 


\section{Obevisto}

ISSN n² 2447-4266

Vol. 1, n 2, Setembro-dezembro. 2015

DOI: http://dx.doi.org/10.20873/uft.2447-4266.2015v1n2p194

componentes dessa rede participam motivados por um interesse comum que dinamiza e mantém as relações em funcionamento: captação de fluxo turístico. Eis o que interessa tanto à iniciativa pública, quanto à privada: captar turistas, fazer com que eles visitem para conhecer o local, gastar ou investir na cidade, região ou país.

Neste contexto, a rede de serviços considerada como "rede turística" por Silva, (2000), apresenta o potencial de integração comercial necessária para o desenvolvimento do setor do turismo, contribuindo tanto para o crescimento como o próprio desenvolvimento econômico da região.

\section{Vale do Paraíba Paulista}

A partir do século XIX o Vale do Paraíba teve significativa mudança em sua história e em seu tecido social, a produção cafeeira foi o motor desse desenvolvimento resultando em fortalecimento econômico e político regional. Com suas abundantes terras virgens e um clima favorável e propícia para a plantação de café, a região foi se povoando por meio de casarões dos barões e de colônias de escravos utilizados no cultivo da planta.

A sua região localizada entre o eixo conhecido hoje como Rio - São Paulo se tornou a principal região de produção cafeeira desde o segundo Império quando atingiu o seu apogeu, o Vale tinha características bastante favoráveis para o seu cultivo sua propagação foi quase que simultâneo por todo o Vale compreendido pela região paulista e fluminense.

Milliet apud Ricci (2006) descreve que os barões e sua ascensão política sobre a sociedade brasileira, foram resultados desta prosperidade se mantendo por meio do plano político até o século $\mathrm{XX}$, e conseguiu estabelecer a valorização do produto no mercado estrangeiro por meio da retenção de estoques dos excedentes produzidos. 


\section{Observistotório}

ISSN n² 2447-4266

Vol. 1, n 2, Setembro-dezembro. 2015

DOI: http://dx.doi.org/10.20873/uft.2447-4266.2015v1n2p194

Ainda no século XIX, outro fator contribuía para o desenvolvimento da economia cafeeira no vale, o crédito assumia esse papel fundamental através de empréstimos em longo prazo com baixas taxas de juros. As formas de financiamento aos cafeicultores, demais agricultores e comerciantes passaram por mudanças significativas nesse período. (MARCONDES, 2002).

Ricci (2002) comenta que no período final, 1920/1935, a população da região decresceu no geral, fruto da decadência definitiva da produção cafeeira. Nesse contexto, o município que experimentou a maior evolução populacional foi Jacareí, observa-se um processo de urbanização crescente, a população, particularmente a parcela urbana, gerou necessidades de consumo, tais como roupas, calçados, chapéus, gravatas, cobertores, entre outros produtos que só seriam atendidas com a produção industrial.

Consideramos, com base na análise anterior, que essa escassez de capital, considerando-se as condições regionais, não foi tão intensa e permitiu aos municípios pioneiros da industrialização regional, com exceção de Jacareí, o desenvolvimento de uma atividade industrial embrionária a partir dos capitais regionais. ( $\mathrm{RICCl}, 2000)$.

Portanto, sem dúvida essa população auxiliava a constituição de um mercado de consumo interno embora sutil. No entanto, o fato mais importante com a decadência cafeeira é que toda a mão de obra utilizada no cultivo cafeeiro da região do Vale migrou para as cidades do oeste-paulista onde o cultivo do café despertou nova perspectiva para essa região.

Entretanto Ricci (2002) afirma como alguns autores que embora o desenvolvimento da economia cafeeira tenha sido relevante para o desenvolvimento do Vale do Paraíba, a escassez de capital no Vale do Paraíba, justifica a sua estagnação econômica. 


\section{Obsevisto}

ISSN n² 2447-4266

Vol. 1, n² 2, Setembro-dezembro. 2015

DOI: http://dx.doi.org/10.20873/uft.2447-4266.2015v1n2p194

\section{Dados Socioeconômicos da Microrregião de Bananal}

Os municípios que constituem a microrregião de Bananal são considerados pequenos em termos de população, Bananal entre os municípios é o mais populoso, apresenta pouco mais de 10.000 habitantes. De acordo com a tabela populacional da microrregião de Bananal os municípios de Areias, Bananal e Silveiras apresentam evolução crescente anual, enquanto que os municípios de Arapeí e São José do Barreiro apresentam quadro decrescente entre o período de 2005 - 2011.

Tabela 4 - População

\begin{tabular}{|c|c|c|c|c|c|c|c|}
\hline \multirow[b]{2}{*}{ Municípios } & \multicolumn{7}{|c|}{ População } \\
\hline & 2005 & 2006 & 2007 & 2008 & 2009 & 2010 & 2011 \\
\hline Arapeí & 2550 & 2535 & 2528 & 2521 & 2506 & 2494 & 2482 \\
\hline Areias & 3668 & 3684 & 3694 & 3691 & 3687 & 3695 & 3705 \\
\hline Bananal & 10007 & 10062 & 10117 & 10161 & 10199 & 10219 & 10272 \\
\hline $\begin{array}{l}\text { São José do } \\
\text { Barreiro }\end{array}$ & 4119 & 4117 & 4115 & 4100 & 4090 & 4078 & 4072 \\
\hline Silveiras & 5617 & 5671 & 5711 & 5741 & 5768 & 5788 & 5831 \\
\hline
\end{tabular}

Fonte Fundação SEADE, organizado pelo autor, 2012

A renda per capita dos municípios da microrregião de Bananal é baixa quando comparada com a cidade de São José dos Campos que possui renda de 1,38 vezes superior em relação ao munício de Bananal a maior renda per capita da região.

Tabela 5 - Renda per capita dos municípios em 2012

\begin{tabular}{l|l|l} 
Município & Renda per capita (em R\$) & Salários mínimos \\
\hline Arapeí & 628,22 & 1,01 \\
\hline Areias & 827,26 & 1,33 \\
\hline Bananal & 1076,06 & 1,73 \\
\hline São José do Barreiro & 1038,74 & 1,67 \\
\hline Silveiras & 895,68 & 1,44
\end{tabular}

Fonte Fundação SEADE, organizado pelo autor, 2012 


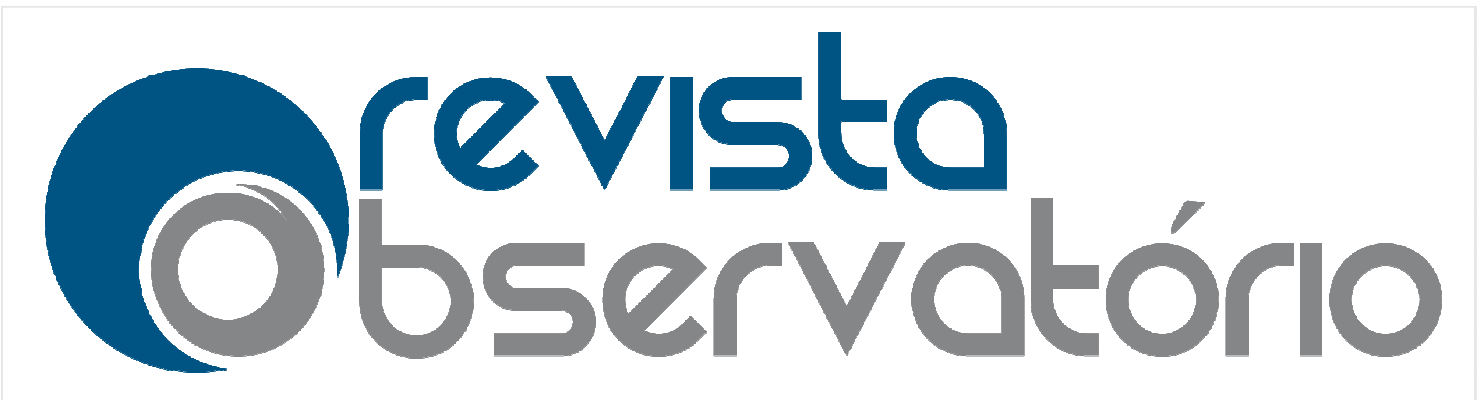

ISSN n² 2447-4266

Vol. 1, n² 2, Setembro-dezembro. 2015

DOI: http://dx.doi.org/10.20873/uft.2447-4266.2015v1n2p194

O Índice de Desenvolvimento Humano (IDH) é uma medida comparativa utilizada para classificar os municípios pelo seu grau de desenvolvimento humano, A estatística é composta a partir de dados de expectativa de vida ao nascer, educação e renda per capita como indicador do padrão de vida. $\mathrm{O} I \mathrm{DH}$ varia de 0 a 1 e quando seu índice for mais próximo de 1 , significa que melhor é a qualidade de vida do município.

A classificação do IDH pelos municípios da microrregião de Bananal comparados com os 645 municípios do Estado de São Paulo foi ruim em relação à amostragem do ranking de 2000.

Tabela 6 - Índice de Desenvolvimento Humano Municipal - 2000

\begin{tabular}{l|l|l} 
Município & Índice de Desenvolvimento Humano- IDH & Ranking 2000 \\
\hline Arapeí & 0,716 & 624 \\
\hline Areias & 0,723 & 619 \\
\hline Bananal & 0,758 & 485 \\
\hline São José do Barreiro & 0,727 & 615 \\
\hline Silveiras & 0,721 & 621
\end{tabular}

Fonte Fundação SEADE, organizado pelo autor, 2012

\section{Fazendas do Café: Espaço, Territorialização e Lugar}

A partir de um trabalho de conquista, com dificuldades e lances aventurosos, o sargento-mor Francisco de Melo Palheta, voltando de uma missão que the foi confiada, em 1727, pelo governador do Maranhão, João de Maria Gama, trouxe para o Brasil da Guiana Francesa, as primeiras mudas de café (BOTELHO, 1984).

Os primeiros canteiros foram utilizados em cultivos ornamentais das chácaras de Belém do Pará. Sua trajetória percorreu Estados vizinhos, passando pela Bahia em 


\section{Obevisto}

ISSN n² 2447-4266

Vol. 1, n², Setembro-dezembro. 2015

DOI: http://dx.doi.org/10.20873/uft.2447-4266.2015v1n2p194

1770 e seguindo ao Rio de Janeiro onde teve sua cultura ampliada pelo Bispo D. Joaquim e Marquês do Lavradio, vice-rei (BOTELHO, 1984).

As plantações de café se expandiram pela Serra do Mar, atingindo o Vale do Paraíba no começo de 1810, no seu caminho, em busca de novas terras, a cultura do café teve sua entrada no Estado de São Paulo, ajudando a sustentar a Monarquia, a abolir a escravidão e a financiar a República.

Segundo Botelho (1984), após muito tempo, com aproximadamente cem anos do início do plantio, passou a liderar a exportação, superando o couro, o açúcar e o algodão, as condições para seu cultivo eram totalmente favoráveis para o desenvolvimento do café, a região tinha mão-de-obra abundante, altitude, solo fértil e temperatura adequadas para um processo rápido no seu crescimento.

Segundo Telles (2006) as primeiras fazendas de café eram totalmente revestidas pela mata, o que exigia do investidor em abrir uma fazenda um grande trabalho inicial: o desmatamento e o destocamento. Isso antes de qualquer outra providencia, tal como seria a própria construção de um pouso para abrigar, ao menos nos primeiros tempos, os proprietários, suas famílias e seus auxiliares, além dos escravos.

Suas edificações tinham como base o planejamento do rego para a condução da água, do qual dependia toda a ordenação das edificações das residências, mas também dos sítios onde este rego atenderia a roda d'água, para o engenho e demais dependências de trabalho. Suas construções eram feitas com madeira resultante do desmatamento a ser feito no próprio local, seus cômodos tinham vinte e quatro palmos em quadro, equivalente a um quadrado de $3,3 \mathrm{~m}$ de lado para atender a quatro solteiros ou a um casal com filhos.

A frente das casas geralmente havia varandas corridas, para que os negros ao saírem não se molhassem em dias de chuva, podendo adoentar-se. Ainda nas 


\section{Obsevisto}

ISSN n² 2447-4266

Vol. 1, n 2, Setembro-dezembro. 2015

DOI: http://dx.doi.org/10.20873/uft.2447-4266.2015v1n2p194

construções, as senzalas deveriam ser localizadas em lugares sadios, enxutos e ventilados, pois era necessária a conservação da escravatura para a prosperidade das fazendas.

O modo de escolha do sítio para a instalação da fazenda, era a partir do conhecimento das árvores capazes de definir se a terra era boa ou não para a cultura do café. Os terrenos ondulados bem ensolarados eram propícios para a sua cultura.

Botelho (1984) ao descrever a formação de uma fazenda de café, principiava a partir da posse da terra, que nos primeiros tempos era feita através da concessão de sesmarias, outorgadas durante o Império e a República, ou pela posse de fato com o uso das terras. O tipo preferido de terra para a cultura do café é o das matas pela qualidade intrínseca que possui e que permite o crescimento de grandes árvores e também, pela umidade com que gerava o apodrecimento orgânico das plantas, folhas e troncos (BOTELHO, 1984)

Durante muito tempo, o costume foi explorar novas terras, só mais a frente por volta de 1900, é que se pensou em recuperar as já utilizadas, adubando-as com esterco animal ou palha de cereais. Os trabalhos preliminares de abertura da fazenda incluem vários serviços: derrubar, arar e plantar. A cultura cafeeira trouxe sua própria tecnologia de plantio, tendo sido um atrativo para mão-de-obra não qualificada pela facilidade no seu cultivo.

\section{Estrada Real - Caminho Novo da Piedade}

A construção de caminhos destinados ao transporte do ouro produzido no interior da colônia portuguesa na América, durante o século XVIII, deve ser entendida no contexto das preocupações da coroa portuguesa em manter rígido controle sobre o transporte de metais preciosos do interior da colônia para o litoral. Pretendia 


\section{Obevisto}

ISSN n² 2447-4266

Vol. 1, n 2, Setembro-dezembro. 2015

DOI: http://dx.doi.org/10.20873/uft.2447-4266.2015v1n2p194

assim, fiscalizar o trânsito de pessoa, garantir a cobrança de tributos e desenvolver sua política colonialista. (TOLEDO 2009, p.15).

Toledo (2009) revela que neste cenário, destacam-se as estradas reais. Caminhos que surgem no final do século XVII, após as primeiras descobertas de ouro em Minas Gerais, foram ampliados, melhorados e dinamizados durante o século XVIII em virtude da intensificação da circulação de riquezas no Brasil colônia. No século seguinte, contribuíram para o escoamento de produtos agrícolas, especialmente do café.

Os caminhos do ouro eram as únicas vias autorizadas para circulação de pessoas, mercadorias e transportes de metais preciosos. Adquiriram caráter oficial e acabaram sendo denominados de Estrada Real. Essas estradas foram responsáveis por tal formação de uma rede viária no Brasil, unindo as capitanias de Minas Gerais, Bahia, São Paulo e Rio de Janeiro, foi elemento importante na organização do mercado interno, estimulando o comercio e a economia de diferentes partes da região.

Reis comenta que as autoridades portuguesas tinham preocupação com o transporte do ouro que desciam a Serra do Mar para depois serem transportados, via marítima para o Rio de Janeiro, o que fez com que os fosse autorizado à abertura de um novo caminho que ligasse a Capitania de São Paulo ao Rio de janeiro sempre por terra, evitando assim o litoral, local frequentado pelos corsários. (REIS, 1971).

Santos (2007) defende a posição de que evidências históricas questionam a visão tradicional em que a Estrada Real era o caminho que ligava as regiões mineradoras ao litoral, e mostra que um conjunto de vias terrestres integrou, em períodos distintos, diferentes regiões brasileiras. Nessa perspectiva de análise historiográfica, amplia-se a visão de Estrada Real para Estradas Reais, consideradas como um conjunto de vias terrestres, que integrou em períodos distintos, atendendo 


\section{Obevisto}

ISSN n² 2447-4266

Vol. 1, n², Setembro-dezembro. 2015

DOI: http://dx.doi.org/10.20873/uft.2447-4266.2015v1n2p194

a diversas necessidades e atividades econômicas, como a pecuária, a mineração e a cafeicultura, em diferentes regiões brasileiras.

Partindo da cidade de Freguesia da Piedade, atual município de Lorena o Caminho Novo da Piedade, ligava a capitania de São Paulo a do Rio de Janeiro, por via terrestre, construída durante o século XVIII, para conduzir o ouro produzido em Goiás e Mato Grosso, desviando do litoral de São Paulo, evitando os perigos do mar e dos piratas, bem como realizar o transporte, evitar os extravios do ouro e facilitar as comunicações entre as duas capitanias.

O caminho novo da Piedade foi o principal fator para a conquista e fixação do homem em grande trecho do vale médio Paraíba. Sem esse desbravamento, não haveria se erguido a civilização do café, impulsionado pelos governos da Capitania de São Paulo que ofereceram grandes vantagens aos que se fixarem às margens do Caminho Novo, o interesse não era apenas pela construção deste caminho, mas também na sua conservação. (REIS, 1971).

O caminho só foi concluído em 1778, construído por iniciativa da Capitania do Governador de São Paulo, Rodrigo César de Menezes dando início a ocupação do território vale-paraibano e a formação de estrutura socioeconômica cuja influência foi relevante nos primeiros anos do Império brasileiro. A sua função original de transportar metais havia perdido o sentido em face de decadência da produção, para o transporte do gado enviado para abastecimento da cidade do Rio de janeiro, e preencheu nova e importante função: a de transportar café. Sua singularidade pode ser considerada como um modelo de transição, diferenciado por suas peculiaridades próprias apontadas e por sua projeção alcançada no cenário regional brasileiro, isto a tornará atraente e cada vez mais importante o estudo a recuperação da sua história, o reconhecimento de suas influências no passado e das 


\section{Obevisto}

ISSN n² 2447-4266

Vol. 1, n 2, Setembro-dezembro. 2015

DOI: http://dx.doi.org/10.20873/uft.2447-4266.2015v1n2p194

possibilidades que se abrem com vistas de reutilização com propósito turístico para a atualidade. (TOLEDO, 2009).

Hoje, o que foi conhecido como caminho do ouro e mais tarde do café, podem ser aproveitados, a pesquisa histórica pode ser um dos requisitos fundamentais para alavancar o setor de turístico como uma rota histórica em busca do desenvolvimento sustentável da região.

Toledo (2009) conclui ao afirmar que de acordo com as necessidades do tempo presente, recuperar o passado e dele extrair fundamentos que permitam projetar, com maior clareza e de forma consciente, as ações que levarão a construção do futuro mais equilibrado e sustentável.

\section{Conclusão}

O Vale do Paraíba Paulista foi cenário para o desenvolvimento econômico da região e do país tendo como motor o ciclo do café e os caminhos para escoamento de todas suas riquezas. No desbravamento das terras da região, incentivado pelos governantes da Capitania de São Paulo surgiram ao longo do novo caminho núcleos urbanos a partir de paradas e ranchos para tropeiros e, assim, estabeleceu-se a "Estrada Real: Caminho Novo da Piedade", objeto deste trabalho.

Após a época áurea do café a região entra em pleno declínio permanecendo apenas sua história, porém, com o passar do tempo surge o turismo contemporâneo como atividade econômica de maneira relevante para a região do Vale do Paraíba Paulista, já que espaços como fazendas, caminhos coloniais e municípios se voltam para a prática da atividade turística, explorando sua história, cultura, edificações, recursos naturais e manifestações culturais como uma alternativa ao processo econômico da região. 


\section{Observistotório}

ISSN n² 2447-4266

Vol. 1, n², Setembro-dezembro. 2015

DOI: http://dx.doi.org/10.20873/uft.2447-4266.2015v1n2p194

O turismo como atividade econômica é percebido a partir de fatores que colaborem para a economia de uma localidade por meio de mecanismos que possam modificar seu quadro socioeconômico tais como: a demanda de empregos com a diminuição de mão de obra desempregada, a preservação de seus recursos naturais e histórico-culturais e principalmente no aumento de divisas através da prestação dos serviços.

Os municípios da microrregião de Bananal estão em permanente estado de concorrência na busca pela assertividade no desenvolvimento da atividade turística tentando explorar seus recursos para atrair e fortalecer o turismo na região. Diante disso, ao considerar as semelhanças e especificidades entre as cidades da microrregião, os municípios visam formar uma unidade integrada e articulada através de um circuito turístico podendo facilitar a melhora dos problemas socioeconômicos como a redução populacional urbana e rural, educação, fatores ligados ao bem estar, etc., com aproveitamento de suas diferenças transformando-as em um recurso estratégico para o desenvolvimento regional.

Na literatura específica, autores descrevem a atividade turística como uma fonte geradora de renda para cada localidade, uma possível solução para os municípios por meio dos seus recursos naturais e histórico-culturais na promoção do seu desenvolvimento.

Entretanto, seus resultados ficam reféns da articulação intrínseca de cada município, no município de Bananal, por exemplo, foi visto que há falta desta união, pois, o poder público tem passado por uma crise financeira, sua renda baseada em impostos arrecadados e subsídios governamentais é insuficiente para sua administração e seu déficit acaba sendo acumulativo.

O turismo pode beneficiar os municípios que apresentarem propostas de benfeitoras às cidades por meio de recursos e programas que promovam seu 


\section{Obevisto}

ISSN n² 2447-4266

Vol. 1, n 2, Setembro-dezembro. 2015

DOI: http://dx.doi.org/10.20873/uft.2447-4266.2015v1n2p194

desenvolvimento. Esses recursos são disponibilizados pelas esferas federal e estadual, todavia é necessário que estas administrações estejam organizadas e em dia com seus pagamentos.

Cabe ressaltar que a vocação turística do Vale do Paraíba Paulista se dá pela somatória de seus recursos turísticos, neste sentido destacam-se aspectos essenciais, ou seja, o turismo só acontece através de dois temas: manifestações culturais ou naturais.

Essa consideração se faz importante já que no Vale do Paraíba Paulista, há os dois tipos presentes e evidenciados tais como: museus, edificações históricas, festas folclóricas, musicais e religiosas, artesanato e demais produções associadas ao turismo. E a natural representada pela Estação Ecológica da Bocaina, serras, trilhas, rios, represa, cachoeiras, fauna e flora.

Este trabalho proporcionou maior conhecimento da atividade turística e seu funcionamento na microrregião do Bananal. A partir deste estudo, passou-se a compreender a economia do turismo, sua importância e relevância para a região do Vale Histórico.

Portanto, ao estudar os mecanismos que possam permitir um desenvolvimento turístico em toda microrregião de Bananal, serão necessárias ações como, o planejamento turístico estratégico, políticas públicas, e a rede de produção do Vale Histórico.

\section{Referências}

AMIN, A. Repensando El Desarrollo Regional. Contribuciones globales para uma estratégia latina americana. Editores Miño y Dávila. Buenos Aires: 2008.

ARAGÃO, S. Ensaio sobre a casa brasileira do século XIX. São Paulo: Blucher, 2010. 


\section{Obevisto}

ISSN n² 2447-4266

Vol. 1, n² 2, Setembro-dezembro. 2015

DOI: http://dx.doi.org/10.20873/uft.2447-4266.2015v1n2p194

BARRETO, M. Turismo e legado cultural: As possibilidades do planejamento. Campinas: Papirus, 2000.

BENI, M. C. Análise Estrutural do Turismo. 13ª ed. São Paulo: SENAC, 2008.

BOTELHO, C. M. de A. Fazendas paulistas do ciclo do café:1756-1928, Rio de Janeiro: Nova Fronteira, 1984.

BOURDIEU, P. O Capital Social: notas provisórias. In; NOGUEIRA, Maria Alice \& CATANI, Afranio. Escritos de Educação. Petrópolis, 1998: Vozes.

BROTHERTHON, B.; WOOD, R. C. Hospitalidade e administração da hospitalidade. In: LASHLEY C.; MORRISON, A. (orgs). Em Busca da Hospitalidade: perspectivas para um mundo globalizado. Barueri, SP: Manole, 2004.

CARMO, E. S. O Espaço do Fenômeno Turismo no Contexto Atual. In: RUSCHMANN, D. V. M; SOLHA, K. T. Planejamento Turístico. Barueri, SP: Manole, 2006.

CARRILHO, M. J. Fazendas de café oitocentistas no Vale do Paraíba. An. mus. paul. [online]. 2006, vol.14, n.1, pp. 59-80. ISSN 0101-4714.

CORIOLANO, L. N. M. T.. Da sedução do turismo ao turismo de sedução. In: Rodrigues, A. B. Turismo, modernidade, globalização. São Paulo: Hucitec, 1997, p.119-135.

CRUZ, R. de C. A. da. Hospitalidade Turística e Fenômeno Urbano no Brasil: Considerações Gerais. In: DIAS, C. M. de M. (Org.) Hospitalidade Reflexões e Perspectivas. Barueri, SP: Manole: 2002.

KON, A. Economia de serviços: teoria e evolução no Brasil: Inclui uma análise sobre o impacto do setor de serviços no desenvolvimento econômico. Rio de Janeiro: Elsevier, 2004.

LAGE, B. H. G; MILONE, P. C. Economia do Turismo. $7^{a}$. ed. Rev e Ampl. São Paulo: Atlas, 2001.

LAKATOS, E. M.; MARCONI, M. de A. Fundamentos de metodologia científica. 7. ed., São Paulo: Atlas, 2010. 


\section{Orevisto}

ISSN n² 2447-4266

Vol. 1, n 2, Setembro-dezembro. 2015

DOI: http://dx.doi.org/10.20873/uft.2447-4266.2015v1n2p194

MAMBERTI, M. M. S. PLANEJAMENTO REgIONAL DO TURISMO NO VALE DO PARAÍBA: ESTUDO DE CASO NA MICRO-REGIÃO DE BANANAL - SP. 2006. 79 P. DISSERTAÇÃO (MESTRADO EM INSTITUTO DE GEOCIÊNCIAS E CIÊNCIAS EXATAS) UNIVERSIDADE ESTADUAL PAULISTA. RIO CLARO - SP.

MARCONDES, R. L. O financiamento hipotecário da cafeicultura no vale do Paraíba paulista (1865-87). Rev. Bras. Econ. [online]. 2002, vol.56, n.1, pp. 147-170. ISSN 0034-7140.

MINISTÉRIO DO TURISMO Evolução mensal da receita e despesa cambial turística no

brasil.,2011.Disponívelem:<http://www.dadosefatos.turismo.gov.br/dadosefatos/hom e.html>. Acesso em: 22 set. 2011.

PORTO, L de A. N. BANANAL NO IMPÉRIO: FAMÍLIA E FAZENDAS. Rio de Janeiro: Editora Brasil-América S.A., 1994.

PUTNAM, R. D. Comunidade e Democracia: a experiência da Itália Moderna. $4^{\mathrm{a}}$ ed. Rio de Janeiro: Editora FGV, 2005.

REIS, P. P.dos. O CAMINHO NOVO DA PIEDADE NO NORDESTE DA CAPITANIA DE S. PAULO. Imprensa Oficial do Estado, São Paulo, 1971.

$\mathrm{RICCl}$, F. A economia cafeeira e as bases do desenvolvimento no Vale do Paraíba Paulista. Revista de história econômica e economia regional aplicada. Juiz de Fora, v. 1, n. 1, 30 nov. 2002.

ROSA, C. A. Como elaborar um plano de negócios. Brasília: SEBRAE, 2007.

SANTOS, M. As estradas Reais. Revista História Viva - Edição Especial, temática n.4, Estrada Real. São Paulo: Duetto Editorial, 2007.

SEN, A.; KLIKSBERG, B. As Pessoas em Primeiro Lugar: A Ética do Desenvolvimento e os Problemas do Mundo Globalizado. São Paulo: Companhia da Letras, 2010.

SILVA, F. de P. S. da. Turismo em rede; uma teia de múltiplas relações - O XXIV Congresso da ABAV. Salvador: Faculdade de Turismo da Bahia, 2000. 


\section{revisto \\ Qbervatório \\ ISSN n² 2447-4266 \\ Vol. 1, n², Setembro-dezembro. 2015 \\ DOI: http://dx.doi.org/10.20873/uft.2447-4266.2015v1n2p194}

SPOSITO, M. E. B. Capitalismo e urbanização, 11ª ed. São Paulo: Contexto 2001.

TELLES, A. C. da S. O Vale do Paraíba e a arquitetura do café. Rio de Janeiro: Capivara, 2006.

TOLEDO, F. S. Estrada Real: Caminho Novo da Piedade, Campinas, SP: Ed. Alínea, 2009.

TORRENTES, P. A. A atividade turística e a preservação do patrimônio histórico e cultural na Estrada Real Paraty-Cunha. 2007. 152 P. Dissertação (Mestrado Em Arquitetura) - Faculdade De Arquitetura E Urbanismo Da Universidade Federal Do Rio De Janeiro. Rio De Janeiro.

VERGARA, S. C. Projetos e relatórios de pesquisa em administração. São Paulo: Atlas, 2000.

XIMENES, T. Capital social, redes sociais e inovações produtivas. Ambient. soc. [online]. 2008, vol.11, n.2, pp. 389-404. ISSN 1414-753X.

Zancheti, S. M. Financiamento da regeneração de áreas urbanas patrimoniais na América Latina. Recife: CECl - Centro de Estudos Avançados de Conservação Integrada, 2011. 115 p. Disponível em: <http://http://www.cecibr.org/ceci/br/publicacoes/outras-publicacoes/380-tecnicas-construtivastradicionais>. Acesso em: 18 abr. 2012.

Acesse esse e outros artigos da Revista Observatório em:

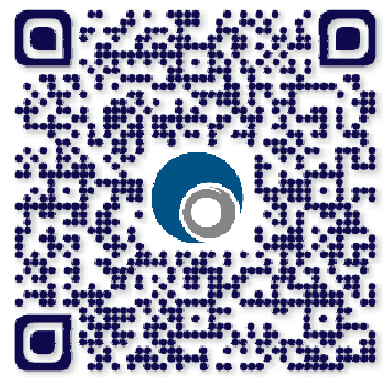

